\section{What is Nanotechnology?}

Nanotechnology is the manipulation of matter on a near-atomic size scale to produce new structures, materials, and devices. Materials exhibit unique properties at the nanoscale level, which affect their physical, chemical and biological behavior.

\section{How is it Used?}

The use of nanotechnology is being researched and developed in many areas, including:

- Developing new optical, electronic and optoelectronic devices.

- Improving energy storage and efficiency.

- Creating highly effective mechanical and bio-electronic interfaces.

- Advancing new methods of medical imaging, treatment, and therapeutics.

Scientists predict nanotechnology has the ability to revolutionize many industries. For example, nanotechnology is expected to enable the production of smaller, cheaper and more accurate sensors. The sensors could detect environmental pollutants, indicate exposure to toxic substances in the workplace, help business track inventories, check food safety, and assess structural damage in buildings.

\section{Is There a Risk in the Workplace?}

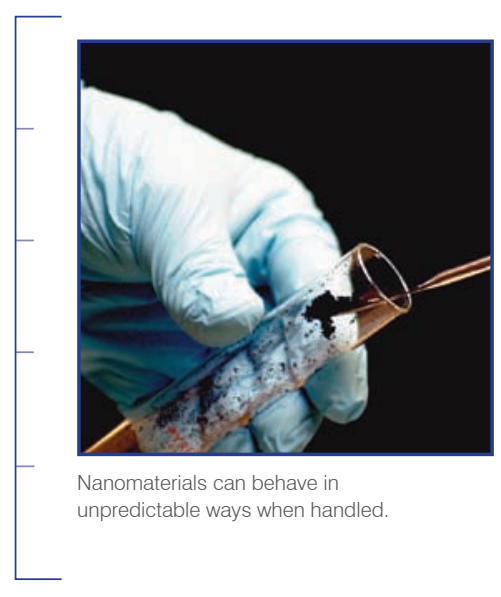

Nanomaterials present new challenges to understanding, predicting and managing potential health risks. They may interact with the human body in different ways than more conventional materials, due to their extremely small size. For example, studies have established that the comparatively large surface area of inhaled nanoparticles can increase their toxicity. Such small particles can penetrate deep into the lungs and may move to other parts of the body, including the liver and brain.

There are still many knowledge gaps to be filled before we fully understand how to work safely with these materials. Until these and other research questions are answered, it is prudent to proceed with caution when working with nanomaterials.

\section{What is NIOSH's Role?}

The National Institute for Occupational Safety and Health is participating in an international effort of research groups, government agencies and industries seeking to understand the health impact of nanotechnology and how to control potential risks. $\mathrm{NIOSH}$ is pursuing a number of initiatives, including:

- Studying the mechanisms leading to nanoparticle toxicity.

- Developing and testing methods to characterize and monitor the healthrelated properties of nanomaterials.

- Investigating nanoparticle exposure and ways of controlling exposure in the workplace.

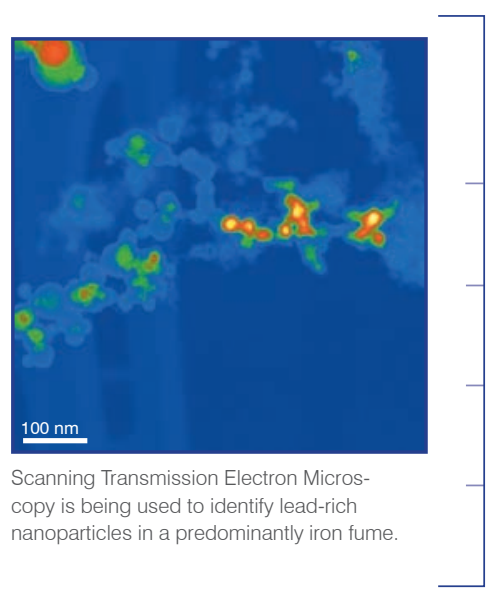

Through strategic planning, working in partnership with others and making information widely available, $\mathrm{NIOSH}$ is working in parallel with the development and implementation of nanotechnology to fulfill its mission of providing national and world leadership to prevent work-related illness and injuries. 


\section{Further Resources}

National Institute for Occupational Safety and Health Nanotechnology Topic Page

www.cdc.gov/niosh/topics/nanotech

National Occupational Research Agenda (NORA). Click on Emerging Technologies www2a.cdc.gov/nora

The National Nanotechnology Initiative in the United States

www.nano.gov

Royal Society/ Royal Academy of

Engineers Report

www.royalsoc.ac.uk

The National Institute for Occupational Safety and Health (NIOSH), which is part of the Centers for Disease Control and Prevention (CDC), is the primary federal agency responsible for conducting research and making recommendations for the prevention of workrelated illness and injuries.
A Transmission Electron Micrograph of a 'nanorope' formed

from single walled carbon nanotubes. The image shows the iron

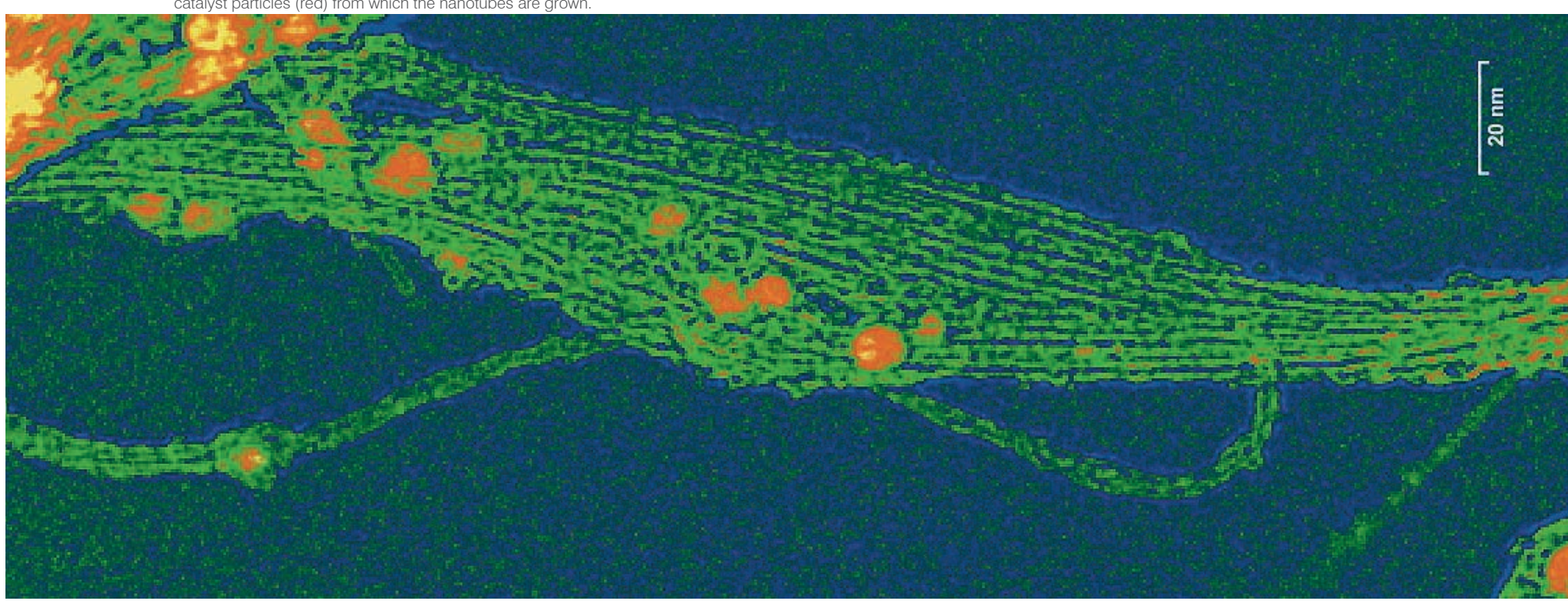

\section{Nanotechnology} Q Workplace Safety 03 and Health

Safer • Healthier $\bullet$ People ${ }^{\text {TM }}$

For more information on nanotechnology and other occupational safety and health topics contact $\mathrm{NIOSH}$ at: 800-356-4674 • 513-533-8573 (fax) pubstaff@cdc.gov

or visit our web site at www.cdc.gov/niosh

DHHS (NIOSH) Publication No. 2004-175

To protect worker health,

studying how nanoparticles

expo-

safe levels. 